\title{
Gambling Behavior Severity and Psychological, Family, and Contextual Variables: A Comparative Analysis
}

\author{
DIANA CUNHA, PHD \\ Faculty of Psychology and Educational Sciences, University of Coimbra, Coimbra, Portugal \\ BRUNO DE SOUSA, PHD \\ Faculty of Psychology and Educational Sciences, Cognitive-Behavioral Center for Research and \\ Intervention, University of Coimbra, Coimbra, Portugal \\ GABRIELA FONSECA, MA \\ Faculty of Psychology and Educational Sciences, University of Coimbra, Coimbra, Portugal \\ ANA PAULA RELVAS, PHD \\ Faculty of Psychology and Educational Sciences, Social Studies Center, University of Coimbra, \\ Coimbra, Portugal
}

This study compares 3 groups consisting of individuals with no gambling problem, those with some problem, and pathological gamblers, according to the following 4 levels of analysis: social context (i.e., accessibility and social acceptance), family context (i.e., family of origin issues, family functioning, and family quality of life), marital issues (i.e., marital satisfaction and adjustment), and individual issues (i.e., congruence, differentiation of self, and psychopathological symptoms). The study protocol of 8 standardized scales, a sociodemographic questionnaire, and 6 independent questions was administered to 331 adults. The main results indicate that although the 2 groups of nonpathological gamblers exhibited differing levels of gambling severity, they did not differ statistically, suggesting that gambling-related problems were only evident when a pathological level was attained. The pathological gamblers exhibited a greater number of family, marital, and individual difficulties compared to the other 2 groups.

Received October 22, 2015; revised March 2, 2016; accepted May 42016.

Address correspondence to Diana Cunha, Faculty of Psychology and Educational Sciences, University of Coimbra, Rua do Colégio Novo, Apartado 6153, 3001-802, Coimbra, Portugal. E-mail: diicunha@gmail.com 
KEYWORDS context, couple, family, gambling severity, individual

Games of chance, or gambling, involve betting something of value (often money) with the hope of obtaining an even more valuable result (Ferentzy \& Turner, 2013; Petry, 2005; Potenza, 2013). These games are not a recent phenomenon; they have been quite common across a number of societies worldwide since the earliest of times (Kalischuk, Nowatzki, Cardwell, Klein, \& Solowoniuk, 2006; Korn, 2000; Ladouceur, 2002), with references found, for example, in the Egyptian pyramids and the Bible (Ferentzy \& Turner, 2013). Recently, these games have increased in popularity (Kalischuk et al., 2006) due to the appearance and acceptance of TV shows devoted to games of chance (e.g., European Poker Tour, The Big Game, Tudo sobre Poker [All About Poker], and Euromilhões [Euromillions lottery]). This popularity is also evident in the increasingly strong advertising that these shows receive.

In Portugal, this trend toward gambling acceptance has become particularly accentuated in recent years. A number of social communication outlets (e.g., Cabral, 2013; Madeira, 2012) have discussed the significant increases in profits generated by entities that explore gambling, such as Jogos Santa Casa (the lottery games of Santa Casa da Misericórdia). In addition, authors (Brieva, 2006; Clímaco, 2004; Domínguez-Álvarez, 2009) have argued that the current context of socioeconomic crisis could contribute to increases in the appeal of gambling.

Although most people engage in gambling as a form of entertainment with no adverse consequences, gambling is a serious problem for some individuals (Ashley \& Boehlke, 2012; Dickson-Swift, James, \& Kippen, 2005; Weinstock, Massura, \& Petry, 2013). Previous literature references various typologies of gamblers (Custer \& Milt, 1985; González, 1989; Kusyszyn, 1978; McCormick \& Taber, 1987; Moody, 1990; Moran, 1970), many of which are based on the severity of the gambling problem. For example, Shaffer, Bilt, and Hall (1999) posited that there are three levels of gamblers: individuals for whom gambling is not a problem or who have never gambled; individuals who exhibit a moderate gambling problem; and individuals with a serious gambling problem. In contrast, Ochoa and Labrador (1994) categorized gamblers into the following four types: social, professional, problematic, and pathological gamblers. Finally, Ladouceur (2002) categorized gamblers according to the categories of low, medium, and high risk. Based on the latter two systems, Cunha and Relvas (2014a) formulated a typology that combined two criteria, which were the frequency and negative consequences of gambling, resulting in the following four types of relationships: (a) no relationship, in which there is no relationship between an individual and engaging in games of chance, or when such a relationship does exist, it is sporadic and does not result in adverse consequences; (b) relationship of controlled domination, in which the individual has full control with regard to his or her gambling activity; (c) relationship of partial subordination, in which gambling influences a significant part of the individual's life, particularly the financial 
aspects; and (d) relationship of complete subordination, in which the individual is fully under the spell of gambling and has adopted a submissive behavior in this regard, causing a number of serious problems.

These four aforementioned typologies include one further condition in which the consequences of the gambling are magnified and exert a negative impact on the gamblers. This condition is consistent with the concept of pathological gambling (American Psychiatric Association, 2000) or, more recently, gambling disorder (American Psychiatric Association, 2013).

To explain gambling disorder, Cunha and Relvas (2014a) developed the Integrative Systemic Model of Pathological Gambling (ISMPG), which makes it possible to understand the development and maintenance of that problem. This model organizes the evidence from the literature on the subject and interprets it as a coherent whole, and it includes four levels of understanding that influence one another. The first is the social context, referring to the social acceptance of gambling behavior and the availability or accessibility of gambling as factors that influence the development of the problem. The second level highlights the family in two ways: transgenerational and relational. The former might be related to the problem, either positively or negatively, by direct routes (transmission of behavior, thoughts, beliefs, and so on, directly related to gambling, perhaps reflecting gambling habits in the family), or indirect ones (e.g., significance of money in the families of origin). The second part (relational) focuses on the functioning of the gambler's family, emphasizing some factors within it that might be associated with maintenance of the problem (e.g., difficulties with communication and the management of emotions and affections; unsupportive families). On the third level we find the couple. Gambling would be a sign of the existence of disturbance in one or more vital functions of the marital subsystem, with the exercise of control and power in the relationship being indicated as one of these functions. Finally, the last level of analysis is the individual, where factors such as psychological vulnerability are considered. Individual characteristics could enhance or reduce the impact of family relationship and marital patterns, and vice versa, as much as social influences.

This model (Cunha \& Relvas, 2014a) predicts that pathological gamblers show high accessibility and social acceptance of gambling and have more problems with regard to the family context, marital issues, and individual issues compared to the nonpathological gamblers. With regard to the family of origin, the pathological gamblers have higher probability of having a high number of members with pathological gambling. Theoretically, the family of origin of pathological gamblers has higher probability of perceiving games of chance as nonproblematic, and money as highly relevant. Besides, they might promote a negative family environment that is characterized by a high frequency of violent behaviors.

Are these difficulties felt in other less severe forms of gambling problem? This is, do gambling-related problems manifest gradually across a continuum 
of severity (Brieva, 2006; Darbyshire, Oster, \& Carrig, 2001; Desai \& Potenza, 2008; Ladouceur, 2002), or are only the most severe expressions of this problem perceived? For example, studies such as Toneatto et al. (2008) on spontaneous remission of gambling disorder refer to the existence of a positive association between the severity of the gambling and the diversity and severity of consequences associated with it. However, as far as we know, the available literature on gambling disorder has no specific studies to answer those questions. Thus, seeking to fill this gap, based on an integrative and holistic theoretical basis, the ISMPG, the aim of this study is to understand if the difficulties associated with gambling disorder (described in the model) manifest themselves gradually over a continuum of gambling severity, or if, instead, they are only experienced in the extreme forms of gambling problem. To this end, this study compares three types of gamblers, who were categorized according to the South Oaks Gambling Screen (SOGS) (Ciarrocchi, 2001) as having no problem with gambling (NP), some problems with gambling (SP), and pathological gamblers (PG; we opted for the designation of pathological gambler at the expense of the current categorization-gambling disorder-to respect the classification promoted by SOGS). This comparison will be made using the four levels of ISMPG: social context (i.e., accessibility and social acceptance), family context (i.e., family of origin issues, family functioning, and family quality of life), marital issues (i.e., marital satisfaction and adjustment) and individual issues (i.e., congruence, differentiation of self and psychopathological symptoms).

\section{METHOD}

\section{Participants}

The sample consisted of 331 participants who were categorized as follows: 162 NP, 117 SP, and 52 PG (see Table 1). The NP group primarily consisted of women $(n=118,72.84 \%$ ), and members had an average age of 33.58 years $(S D=10.90)$. Most members of this group were single $(n=86,53.08 \%)$, had at least a bachelor's degree level of education ( $n=131,80.86 \%$; United Nations Educational Scientific and Cultural Organization [UNESCO] Institute for Statistics, 2012), resided in primarily urban areas ( $n=140,86.42 \%$; Instituto Nacional de Estatística, 2009), and had a midlevel socioeconomic status (SES; $n=89,54.94 \%$; Simões, 1994). The SP group also consisted primarily of women $(n=49,63.64 \%)$ and members had an average age of 29.03 years $(S D=8.35)$. Most members of this group were single $(n=79,67.50 \%)$, had at least a bachelor's degree level of education ( $n=84,71.8 \%$; UNESCO Institute for Statistics, 2012), resided in primarily urban areas ( $n=98,83.80 \%$; INE, 2009), and had a midlevel SES ( $n=49$, 41.90\%; Simões, 1994) or were students $(n=31,26.50 \%)$. The PG group primarily consisted of men ( $n=43,82.70 \%$ ) and members had an average age of 36.66 years 
TABLE 1 Sample Characterization

\begin{tabular}{|c|c|c|c|c|c|c|}
\hline \multirow{3}{*}{$\begin{array}{l}\text { Variables } \\
\text { Sex }\end{array}$} & \multicolumn{6}{|c|}{ Groups } \\
\hline & \multicolumn{2}{|c|}{ NP } & \multicolumn{2}{|c|}{ SP } & \multicolumn{2}{|c|}{ PG } \\
\hline & $n$ & $\%$ & $n$ & $\%$ & $n$ & $\%$ \\
\hline Female & 118 & 72.84 & 66 & 56.40 & 9 & 17.30 \\
\hline Male & 44 & 27.16 & 51 & 43.60 & 43 & 82.70 \\
\hline Age & $\begin{array}{c}M \\
33.58\end{array}$ & $\begin{array}{c}S D \\
10.90\end{array}$ & $\begin{array}{c}M \\
29.03\end{array}$ & $\begin{array}{l}S D \\
8.35\end{array}$ & $\begin{array}{c}M \\
36.66\end{array}$ & $\begin{array}{c}S D \\
12.66\end{array}$ \\
\hline Marital status & $n$ & $\%$ & $n$ & $\%$ & $n$ & $\%$ \\
\hline Single & 86 & 53.08 & 79 & 67.50 & 21 & 40.38 \\
\hline Married or common law & 63 & 38.89 & 34 & 29.10 & 20 & 38.46 \\
\hline Divorced & 9 & 5.56 & 4 & 3.40 & 11 & 21.15 \\
\hline Widower & 4 & 2.47 & 0 & 0.00 & 0 & 0.00 \\
\hline Education & $n$ & $\%$ & $n$ & $\%$ & $n$ & $\%$ \\
\hline Primary school & 0 & 0.00 & 1 & 0.90 & 1 & 1.92 \\
\hline Lowersecondary education & 7 & 4.32 & 7 & 6.00 & 8 & 15.38 \\
\hline Upper secondary education & 24 & 14.81 & 25 & 21.40 & 20 & 38.46 \\
\hline Bachelor & 62 & 38.27 & 42 & 35.90 & 19 & 36.54 \\
\hline Master & 57 & 35.19 & 35 & 29.90 & 4 & 7.69 \\
\hline $\mathrm{PhD}$ & 12 & 7.41 & 7 & 6.00 & 0 & 0.00 \\
\hline Residence area & $n$ & $\%$ & $N$ & $\%$ & $n$ & $\%$ \\
\hline Primarily urban area & 140 & 86.42 & 98 & 83.80 & 41 & 78.85 \\
\hline Medium urban area & 10 & 6.17 & 13 & 11.10 & 3 & 5.77 \\
\hline Primarily rural area & 5 & 3.09 & 4 & 3.40 & 3 & 5.77 \\
\hline Missing values & 7 & 4.32 & 2 & 1.70 & 5 & 9.62 \\
\hline Socioeconomic status & $n$ & $\%$ & $n$ & $\%$ & $n$ & $\%$ \\
\hline Low & 5 & 3.09 & 7 & 6.00 & 7 & 3.64 \\
\hline Medium & 89 & 54.94 & 49 & 41.90 & 20 & 38.46 \\
\hline High & 30 & 18.52 & 21 & 17.90 & 9 & 17.31 \\
\hline Students & 30 & 18.52 & 31 & 26.50 & 11 & 21.15 \\
\hline Retired & 2 & 1.23 & 1 & 0.90 & 1 & 1.92 \\
\hline Unemployed & 6 & 3.70 & 8 & 6.80 & 4 & 7.69 \\
\hline
\end{tabular}

Note: $\mathrm{NP}=$ no problem with gambling; $\mathrm{SP}=$ some problem with gambling; $\mathrm{PG}=$ problem gamblers.

$(S D=12.66)$. Most members of this group were single $(n=21,40.38 \%)$ or married and had a stable union ( $n=20,38.46 \%)$, had achieved up to an upper secondary education ( $n=20,38.46 \%)$ or earned a bachelor's degree $(n=19$, 36.54\%; UNESCO Institute for Statistics, 2012), resided in predominantly urban areas ( $n=41,78.85 \%$; INE, 2009) and had a midlevel SES ( $n=20,38.46 \%$; Simões, 1994) or were students ( $n=11,21.15 \%$ ).

A one-way analysis of variance (ANOVA) indicated that there was a significant difference among the three types of gamblers, with regard to age, $F(2,331)=11.353, p<.001, \eta^{2}=.07$. A Tukey's post hoc test (Tukey's honestly significant difference [HSD]) comparing SP versus NP and SP versus PG revealed that the members of the SP group were younger than those in the other two groups. A chi-square test showed that the groups also differed with 
regard to gender, $\chi^{2}(2, N=331)=50.203, p<.001, V=-.39$. The Fisher's exact test demonstrated that there were statistically significant differences in the groups' educational levels, $\chi^{2}(2, N=331)=37.818, p<.001, V=.24$, and marital status, $\chi^{2}(2, N=331)=22.990, p<.001, V=.21$. A residual analysis of the chi-square test revealed that the intergroup gender differences were due to a higher number of women than men (residual 2.4/-2.9) in the NP group and the higher number of men than women (residual -3.9/4.6) in the PG group as compared to the expected ratios if the variables were independent. Regarding educational levels, the intergroup difference was due to the greater number of individuals with upper secondary education levels (residual 3.6) and the lower number of individuals with a master's degree (residual -2.9) in the PG group than expected if the variables were independent. Finally, the differences in marital status were due to the greater number of divorced participants (residual 3.7) in the PG group than expected if the variables were independent.

\section{Sample Collection Procedure}

The participants in this study were recruited as follows: (a) gamblers' associations (e.g., Gamblers Anonymous, Families Anonymous) were asked to distribute information regarding this study to their members and invite them to participate. Several copies of the study protocol were provided for distribution among potential participants. (b) The study protocol was available online (via online gaming platforms, social networks, and email) such that any individual of legal age was invited to participate. This method represented the virtual equivalent of the snowball recruiting technique (Goodman, 1961). The participants in the PG group were invited to participate either in person or online, whereas participants in the other two groups only participated online. The invitation to participate included the following information: the study aims, information about compliance with confidentiality and anonymity, details about the voluntary nature of their participation, and contact information regarding the family and couple's therapy services that were available at the investigators' institution that provide free specialized help for pathological gambling. Due to the voluntary nature of individuals' participation and the guarantee of confidentiality and anonymity, the participants were not asked to sign an informed consent form (American Psychological Association, 2002). The only inclusion or exclusion criterion was that participants had to be 18 years or older. The participants were allocated to the study groups based on their scores on the SOGS (cf., Instruments), as follows: $0=\mathrm{NP}, 1$ to $4=\mathrm{SP}$ and 5 or more $=\mathrm{PG}$.

\section{Measures}

The study protocol (see Table 2) consisted of a sociodemographic questionnaire, eight self-report instruments (i.e., Likert scales) adapted for the 


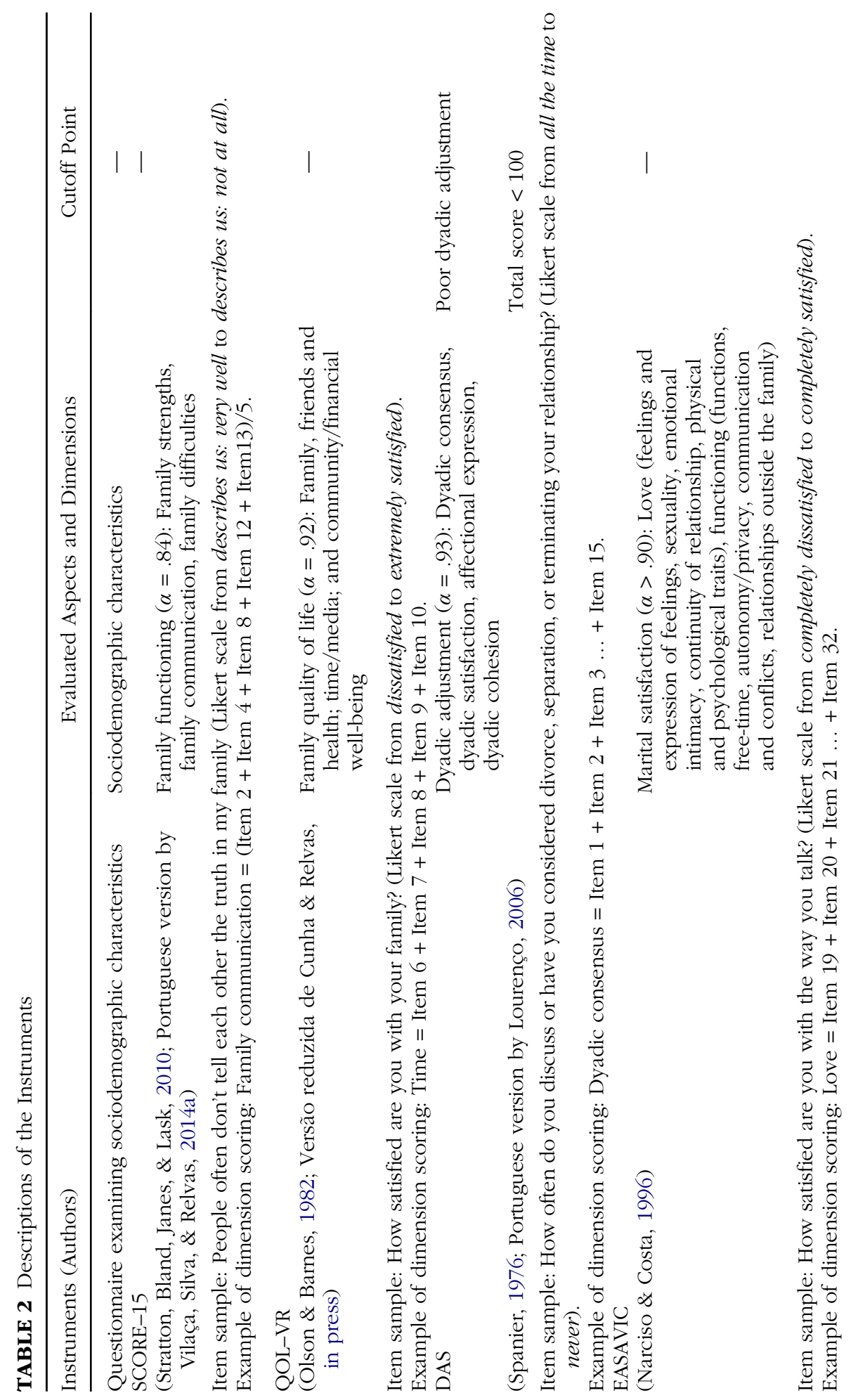




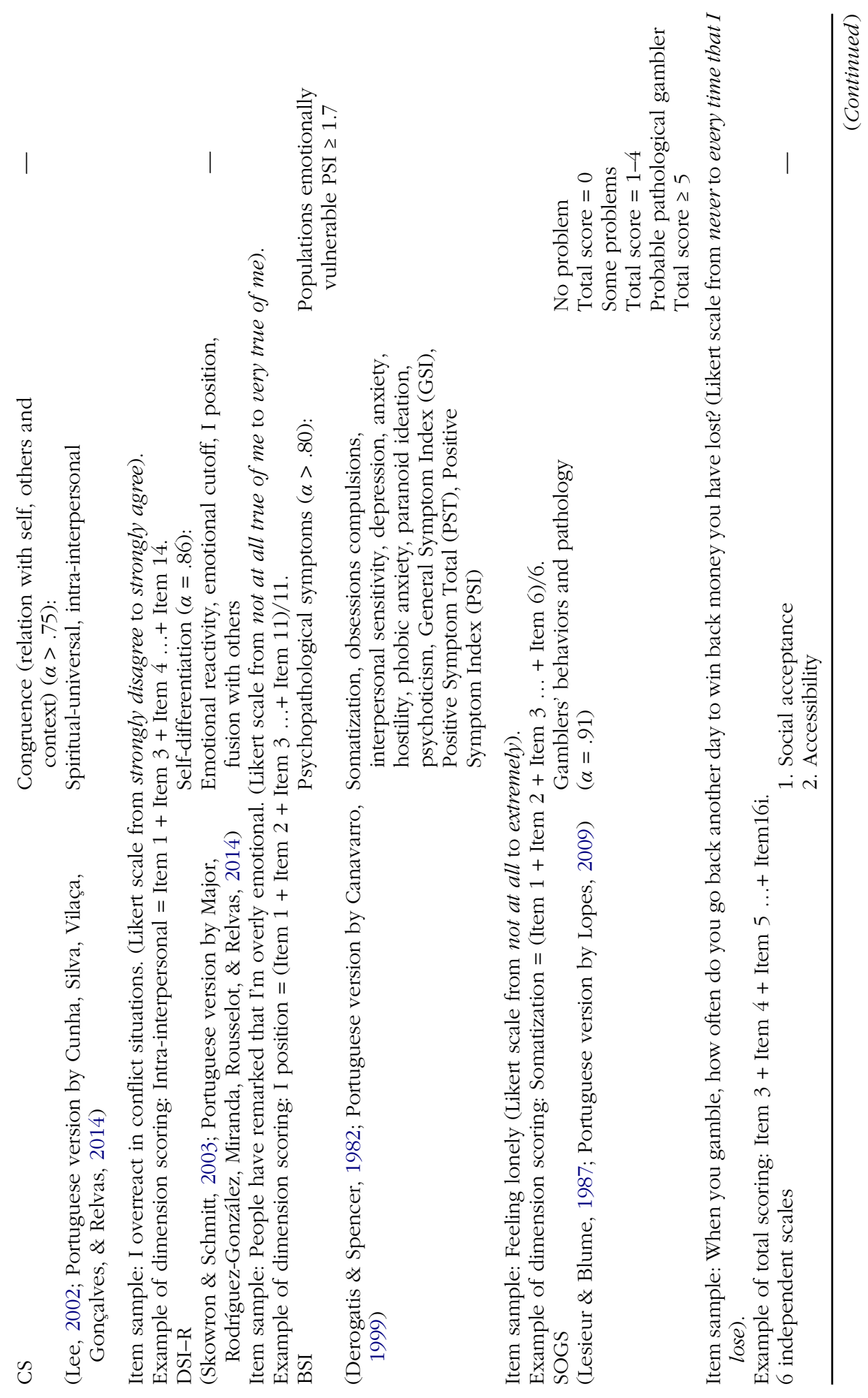




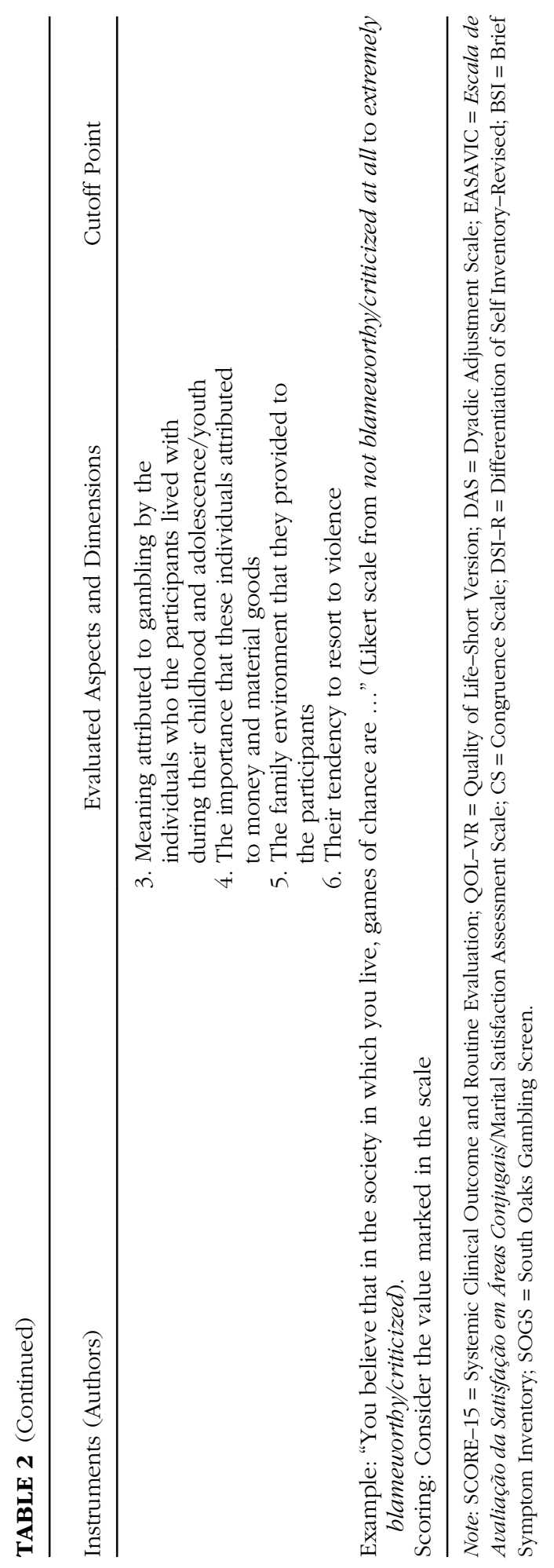


Portuguese population who exhibited satisfactory psychometric properties, and six independent questions (i.e., Likert scales). The instruments queried for information regarding sociodemographic data, family functioning (Systemic Clinical Outcome and Routine Evaluation-15 [SCORE-15]), quality of life (Quality of Life-Short Version [QOL-VR]), dyadic adjustment (Dyadic Adjustment Scale [DAS]), marital satisfaction (Escala de Avaliação da Satisfação em Áreas Conjugais/Marital Satisfaction Assessment Scale [EASAVIC]), congruence (Congruence Scale [CS]), differentiation of self (Differentiation of Self Inventory-Revised [DSI-R]), psychopathological symptoms (Brief Symptom Inventory [BSI]), and gambling behaviors with associated problems (SOGS). In addition, individuals' access to and social acceptance of gambling were evaluated, as well as family of origin issues (with six independent questions).

\section{Statistical Analysis}

Parametric (one-way ANOVA $[F]$ ) and nonparametric (Mann-Whitney $U$ and $\chi^{2} /$ Fisher's exact test and corresponding residual analysis) tests were utilized to compare the groups using the IBM SPSS Statistics software, version 21. Regarding marital status, the PG group exhibited an $n$ equal to 20, but an ANOVA was conducted given that the assumptions regarding the homogeneity of variances and normality were satisfied (Pallant, 2001).

In addition, the PG group was analyzed using a two-step cluster analysis to discriminate the natural groups based on a set of variables, which stabilizes the proximity criterion with a hierarchical agglomerative clustering, the centers of which are distant. A measure of likelihood resulted from the analysis of the selected distances, which defined the normal densities for the continuous variables and the multinomial probability mass functions for the categorical variables (Fraley \& Raftery, 1998). The average silhouette coefficient (which measures how well objects lie within their cluster) was used to measure the goodness of fit (Rousseeuw, 1998). This index combines cohesion (based on the arithmetic mean of the distances between all of the objects in a cluster) and separation (based on the average distance between any one object and the remainder of the objects that were not included in the same cluster). The values for this index range from -1 to 1 , with values close to 0 (zero) indicating inadequate fits, 0 to .2 indicating poor fits, .2 to .5 indicating reasonable fits, and greater than .5 indicating good fits (Rousseeuw, 1998).

Effect sizes were calculated for all of the comparisons that were performed, and the results were categorized according to the following reference values: $V$ and $r\left(.1=\right.$ small effect, $.3=$ medium effect, .5 = large effect; Cohen, 1992)) and $\eta^{2}$ $(.01=$ small effect, $.06=$ medium effect, $.14=$ large effect; Cohen, 1988) .

The significance level was set to $5 \%$ for all of the statistical analyses. 


\section{RESULTS}

\section{Comparisons Among the Groups}

SOCIAL CONTEXT: ACCESSIBILITY AND SOCIAL ACCEPTANCE

Across the three groups, the responses indicated that there was a high level of poor social acceptance and most participants responded that accessibility was "easy." A chi-square test did not detect differences among the groups $(p=.273, p=.784$, respectively).

\section{FAMILY OF ORIGIN}

A Fisher's exact test revealed that there was a statistically significant difference among the groups $(p=.028, V=.16)$ with regard to the third question on the SOGS (i.e., "Check which of the following people in your life has [or had] gambling problems"). A residual analysis showed that this difference was due to a greater number of responses of "More than one of the previous options" in the PG group (residual 2.8) than expected if the variables were independent.

For the next four questions the chi-square test did not detect statistically significant differences among the groups $(p=.122, p=.937, p=.185, p=.354$, respectively): (a) for the question, "The people you lived with during your childhood and adolescence/youth viewed games of chance as ...," most (53.80-65.00\%) responses indicated that perceptions were negative. (b) Most (66.70-75.00\%) of the responses to the question, "The people you lived with during your childhood and adolescence/youth considered money and material goods as ...," were between 4 and 6 points of the scale (i.e., relevant) for all three groups. (c) For the question, "The home environment during your childhood and adolescence/youth was ...," most (75.00-84.60\%) responses were between 4 and 6 points of the scale (i.e., good) for all three groups. (d) The question, "Did the people you lived with during your childhood and adolescence/youth perform violent actions?" revealed that most (82.70-87.00\%) of the participants' families of origin across all three groups did not perform violent actions.

\section{FAMILY FUNCTIONING}

A one-way ANOVA and Tukey's HSD test revealed that there was a significant difference between the PG and NP group and between the PG and SP group with regard to the SCORE-15 (see Table 3), with the total and individual dimensions scores indicating greater levels of family dysfunction in the PG group.

\section{FAMILY QUALITY OF LIFE}

The ANOVA results (see Table 3) revealed that the PG group scored lower with regard to satisfaction with family, friends, and health than the NP and 
TABLE 3 Analysis of Variance results: SCORE-15, QOL-VR, EASAVIC, DAS, CS, DSI-R, and BSI

\begin{tabular}{|c|c|c|}
\hline Variables & Group Comparisons & Effect Size $\left(\eta^{2}\right)$ \\
\hline SCORE-15 total & $F(2,331)=7.198, p=.00$ & .04 \\
\hline Family communication & $F(2,331)=6.095, p=.003$ & .04 \\
\hline Family difficulties & $F(2,331)=5.455, p=.005$ & .03 \\
\hline Family strengths & $F(2,331)=4.111, p=.017$ & .02 \\
\hline QOL-VR total & $F(2,117)=1.769, p=.175$ & - \\
\hline Family, friends and health & $F(2,117)=10.761, p<.001$ & .14 \\
\hline Time & $F(2,117)=0.991, p=.372$ & - \\
\hline Media and community & $F(2,117)=0.877, p=.417$ & - \\
\hline Financial well-being & $F(2,117)=3.375, p=.035$ & .03 \\
\hline EASAVIC total & $F(2,117)=3.616, p=.030$ & .06 \\
\hline Love & $F(2,117)=2.679, p=.073$ & - \\
\hline Functioning & $F(2,117)=5.247, p=.007$ & .08 \\
\hline DAS total & $F(2,117)=6.726, p=.002$ & .11 \\
\hline Dyadic consensus & $F(2,117)=5.186, p=.007$ & .08 \\
\hline Dyadic satisfaction & $F(2,117)=5.555, p=.005$ & .09 \\
\hline Affectional expression & $F(2,117)=1.792, p=.171$ & - \\
\hline Dyadic cohesion & $F(2,117)=4.840, p=.010$ & .08 \\
\hline CS total & $F(2,331)=2.473, p=.086$ & - \\
\hline Intra/interpersonal & $F(2,331)=8.152, p<.001$ & .05 \\
\hline Spiritual/universal & $F(2,331)=0.166, p=.847$ & - \\
\hline DSI-R total & $F(2,331)=9.420, p<.001$ & .05 \\
\hline Emotional reactivity & $F(2,331)=4.824, p=.009$ & .03 \\
\hline I position & $F(2,331)=1.846, p=.160$ & - \\
\hline Emotional cutoff & $F(2,331)=12.238, p<.001$ & .07 \\
\hline Fusion with others & $F(2,331)=5.308, p=.005$ & .03 \\
\hline PSI & $F(2,331)=16.198, p<.001$ & .10 \\
\hline GSI & $F(2,331)=25.458, p<.001$ & .15 \\
\hline PST & $F(2,331)=19.943, p<.001$ & .11 \\
\hline Somatization & $F(2,331)=13.250, p<.001$ & .08 \\
\hline Obsessions-compulsions & $F(2,331)=21.000, p<.001$ & .11 \\
\hline Interpersonal sensitivity & $F(2,331)=11.537, p<.001$ & .06 \\
\hline Depression & $F(2,331)=19.091, p<.001$ & .11 \\
\hline Anxiety & $F(2,331)=16.493, p<.001$ & .09 \\
\hline Hostility & $F(2,331)=22.648, p<.001$ & .12 \\
\hline Phobic anxiety & $F(2,331)=17.285, p<.001$ & .10 \\
\hline Paranoid ideation & $F(2,331)=18.162, p<.001$ & .10 \\
\hline Psychoticism & $F(2,331)=37.796, p<.001$ & .19 \\
\hline
\end{tabular}

Note: SCORE-15 = Systemic Clinical Outcome and Routine Evaluation; QOL-VR = Quality of Life-Short Version; DAS = Dyadic Adjustment Scale; EASAVIC = Escala de Avaliação da Satisfação em Áreas Conjugais/Marital Satisfaction Assessment Scale; CS = Congruence Scale; DSI-R = Differentiation of Self Inventory-Revised; BSI = Brief Symptom Inventory; PSI = Positive Symptom Index; GSI = General Symptom Index; PST = Positive Symptom Total.

SP groups, and these differences were statistically significant $(p<.001)$. In addition, financial well-being scores were lower for the PG group compared to the NP group, and this difference was statistically significant $(p=.035)$.

\section{MARITAL SATISFACTION AND DYADIC ADJUSTMENT}

Regarding marital satisfaction (EASAVIC; see Table 3), the total scores for this factor and for the functioning dimension were lower for the PG group than for 
the other two groups, and this difference was statistically significant $(p=.030$, $p=.007$, respectively).

The PG group also had lower scores on marital adjustment (DAS; see Table 3) than the NP and SP groups for the total score and for the dyadic satisfaction, dyadic consensus, and dyadic cohesion dimensions (these differences were statistically significant). The total score was not lower than 100 in any of the groups (103.49 $\leq M \leq 116.16)$, as this is the cutoff point for considering a poor dyadic adjustment (Spanier, 1976).

\section{INDIVIDUAL FUNCTIONING}

The PG group showed lower scores on congruence (CS; see Table 3), specifically the intra/interpersonal dimension, than the NP and SP groups $(p<.001)$.

The DSI revealed that there were statistically significant results (see Table 3), with the PG group having lower scores than the NP and SP groups for the total scale and for emotional cutoff. Moreover, the PG group had lower scores on the fusion with others than the NP group.

The BSI results (see Table 3) revealed that there were statistically significant differences in the global indexes and across all of the dimensions, with the PG group showing higher levels of symptoms compared to the NP and SP groups. Based on the PSI cutoff for emotionally disturbed populations ( $>$ 1.7; Canavarro, 1999), the PG group $(M=1.88, S D=0.62)$ had the highest probability of experiencing emotional disturbance across the groups.

\section{Cluster Analysis}

A two-step cluster analysis was performed to investigate the presence of empirical groups of pathological gamblers; that is, whether these gamblers constituted a homogeneous group. Sociodemographic (i.e., gender, age, marital status, educational level, place of residence, SES, and type of pathological gambling [clinical vs. nonclinical), family (i.e., total SCORE-15 and total QOLRV scores), marital (i.e., total DAS and total EASAVIC scores) and individual (i.e., total CS, total DSI, BSI-IGS, and total SOGS scores) variables were examined.

The analysis included 17 participants (i.e., corresponding to $85 \%$ of married participants of the PG group) who responded to all of the instruments and were considered to have contributed valid data for analysis. The analysis resulted in two clusters with sample sizes of eight (47.10\%) and nine (52.90\%); the ratio of the larger to the smaller cluster was equal to 1.12. A goodness of fit was achieved with an average silhouette coefficient of 0.5 . The clusters differed from each other with regard to their levels of difficulty associated with psychopathological symptoms (i.e., BSI-PSI), family functioning (i.e., 


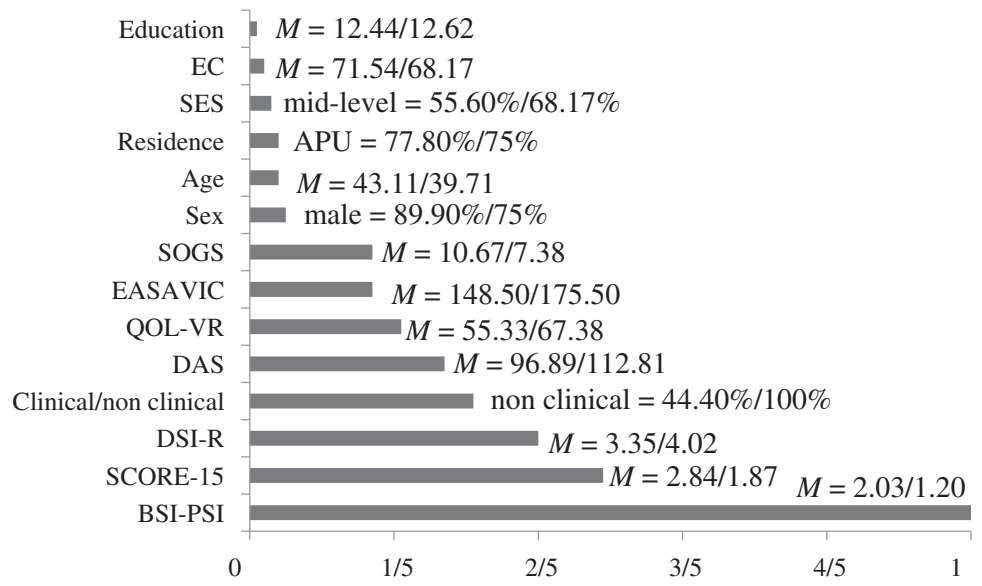

FIGURE 1 Results of the two-step analysis on the pathological gamblers group (Cluster 1/Cluster 2).

total SCORE-15), differentiation of self (i.e., total DSI-R), pathological gambling type (i.e., clinical [gamblers receiving clinical treatment for gambling issues] vs. nonclinical [gamblers not receiving any clinical treatment]), and dyadic adjustment (i.e., total DAS). These variables represented the main predictors with average silhouette coefficients of $1, .49, .40, .31$, and .27, respectively. Comparisons between the clusters (a Mann-Whitney test for the quantitative variables and a chi-square test for the pathological gambling type were used) revealed that the differences with regard to these variables were statistically significant $(p<.05 ; .56<r<.79 ; V=.61$; i.e., large effects). One cluster (designated as the married/severe PG cluster) exhibited higher scores on the BSI and SCORE-15 and lower scores on the DSI-R and DAS; that is, this cluster had greater difficulties compared to the other cluster (designated as the married/mild PG cluster). The married/severe PG cluster consisted of both clinical (55.60\%) and nonclinical (44.40\%) pathological gamblers, whereas the married/mild PG cluster consisted of only nonclinical gamblers. Figure 1 presents the results for the remaining variables (these variables represented weaker predictors and the differences between the clusters were statistically nonsignificant).

\section{DISCUSSION}

This discussion section focuses on the concerns regarding the total scores for the instruments used in this study as a function of the small number of participants in the PG group. 
This study compares three groups of individuals with increasing levels of gambling problem severity. A global analysis revealed that the PG group differed from the nonpathological gambling groups' problems (i.e., the NP and SP groups), particularly with regard to family functioning (i.e., SCORE15), quality of life (i.e., QOL-VR: Family, Friends, and Health), marital satisfaction (i.e., EASAVIC), dyadic adjustment (i.e., DAS), differentiation of self (i.e., DES-R) and psychopathological symptoms (i.e., BSI: total score and psychoticism scale). The PG group was not homogeneous, as it consisted of two clusters: one cluster (with both clinical and nonclinical pathological gamblers) showed more psychopathological difficulties (i.e., BSI) and problems with family (i.e., SCORE-15), differentiation of self (i.e., DSI-R), and marital status (i.e., DAS) compared to the other cluster (with only nonclinical pathological gamblers). The results of this study suggest that gambling-related problems do not manifest gradually along a continuum of severity, as suggested by some authors (Brieva, 2006; Darbyshire et al., 2001; Desai \& Potenza, 2008; Ladouceur, 2002; alternatively, when problems manifest, their expression is not sufficiently detected as differences among the groups included in this study). Manifestation might be at its peak when gambling problems reach high levels of severity (i.e., PG). This direction within the continuum might only be manifested within the PG group. The differences between the PG group and nonpathological groups are consistent with the theoretical basis of this work, the ISMPG.

Based on the aforementioned global considerations, the results of this study are discussed in the order and layout in which they were described. Beginning at the level of analysis corresponding to context, the results about gambling accessibility are completely framed in the current context. In fact, the increased liberalization of gambling over the last decades has led to substantial increases in the availability and accessibility of gambling (Moore, Thomas, Kyrios, Bates, \& Meredyth, 2011). Nevertheless, as pointed out by Clímaco (2004), there still remains a social climate of moral ambivalence in relation to gambling with opinions on the social acceptance of gambling divided between acceptance and criticism.

In this study, the PG group differed from the other two groups in that more than one individual within their sphere of relationships (e.g., close relatives, relatives, and friends) also had gambling problems. According to previous literature examining the transmission of gambling behaviors in families, the PG group should have numerous relatives with gambling problems (e.g., Desai, Potenza, Krishnan-Sarin, \& Cavallo, 2007; Felsher, Derevensky, \& Gupta, 2003). In addition, research has shown the strength of peer influence (Cunha \& Relvas, 2014b), which suggests the need to include this variable in broad-scoped models of pathological gambling, such as ISMPG (Cunha \& Relvas, 2014a). International studies conducted with adolescents (Gupta \& Derevensky, 1997) and adults (Jiménez, 2002) have found that there 
are gambling problems among the acquaintances of pathological gamblers, meaning that there might be a transverse influence of age on gambling.

The remaining variables related to family of origin (e.g., the meaning attributed to gambling, the importance of money, family environment, violence and education) did not exhibit statistically significant differences among the groups. These results are not consistent with previous literature, which has argued that these factors are highly relevant for the development of pathological gambling (e.g., King, Abrams, \& Wilkinson, 2010). Moreover, these findings suggest the importance of the following property of the systems: equifinality. ${ }^{1}$ This property reduces the weight of the past/origin as a determinant of vulnerabilities and shows that, in addition to the characteristics of the origins, the following factors are highly significant: psychopathological vulnerability, differentiation of self (see the current results regarding the DSIR) and ongoing family and marital functioning (see the current results regarding the SCORE-15, and the EASAVIC and DAS, respectively).

The PG group exhibited more family functioning difficulties (i.e., SCORE15) compared to the NP and SP groups. Indeed, pathological gamblers' family functioning has a broad scope of difficulties, including issues related to the expression of feelings, family rules, roles and communication, among others (Ciarrocchi \& Hohmann, 1989; Dowling, Smith, \& Thomas, 2009; Hardoon, Derevensky, \& Gupta, 2002; Kalischuk et al., 2006).

The quality of life dimensions with regard to family, friends, and health (i.e., QOL-VR) are included in this discussion because, despite their dimensionality, they exhibited large effect sizes. According to previous literature (Berger, 2012; Grant \& Kim, 2001; Mythily, Edimansyah, Qiu, \& Munidasa, 2011), the quality of life should be lower in the PG group compared to the groups with the nonpathological gamblers. This prediction is consistent with the following findings: (a) the PG group had more family difficulties (i.e., SCORE-15), and (b) higher levels of psychopathological symptoms (i.e., mental health), which often manifest as physical health problems, particularly problems related to stress-influenced conditions (Ciarrocchi, 1987). In addition, previous literature shows that relationships with friends are affected by pathological gambling (Ciarrocchi, 2001).

Previous literature examining marital issues, specifically the studies that used the DAS (Harvey, Trudel, Poirier-Arbour, \& Boyer, 2007; Lee, 2002b), shows that pathological gamblers have poor dyadic adjustment. As such, the differences evident among the groups in this study with regard to marital satisfaction were expected, as the couple might be the first family subsystem to be affected in the case of married pathological gamblers (Montero \& Megías-Lizancos, 2011).

A number of authors (Bowen, 1978; Kerr \& Bowen, 1988; Patrick, Sells, Giordano, \& Tollerud, 2007) have posited that the differentiation of the self is associated with individuals' ability to maintain intimate relationships. In addition, the differentiation of the self positively correlates with marital satisfaction 
(Peleg, 2008; Skowron, 2000). Therefore, the finding that the PG group had exhibited low levels of differentiation of the self was not surprising. The PG group also had the highest proportion of divorced participants, which suggests that pathological gamblers have difficulty maintaining intimate relationships. The high percentage of divorce among pathological gamblers is widely reported in previous literature (Ciarrocchi, 2001; Lorenz \& Yaffee, 1986). Consistent with the concept of the differentiation of the self (Major et al., 2014), pathological gamblers seem to exhibit greater dependence on other people to reaffirm their beliefs, convictions, and decisions. They are also less emotional and show behavioral detachment from others, which manifests as fear of intimacy or of being suffocated in their relationships. Pathological gamblers also have greater difficulty when establishing their own pondered convictions and show greater tendencies to react to environmental stimuli based on automatic emotional responses.

Psychopathological symptoms were the most significant factor from a statistical perspective. All of the dimensions and global scores indicated that the PG group had higher levels of psychopathological symptoms. These findings are consistent with previous literature showing that emotional disorders are frequently associated with pathological gambling (Barrault \& Varescon, 2012; Jiménez-Murcia et al., 2010; Teo, Mythily, Anantha, \& Winslow, 2007). In addition, psychoemotional vulnerability is one factor associated with the occurrence of pathological gambling (Blaszczynski \& Nower, 2002).

A cluster analysis revealed that the PG group was significantly heterogeneous (i.e., a married/mild PG subgroup and a married/severe PG subgroup), suggesting that it represented a continuum of severity. This heterogeneity was stronger with regard to the individual (i.e., psychopathological symptoms and the differentiation of the self), family (i.e., family functioning), and marital (i.e., dyadic adjustment) variables, whereas the sociodemographic factors included in this study did not play a relevant role in distinguishing between the clusters. Thus, some pathological gamblers are able to live in a fairly adaptive manner, as they exhibit less family (i.e., SCORE-15), marital (i.e., DAS), and individual (i.e., BSI and DSI-R) difficulties and do not seek specialized help (i.e., nonclinical pathological gambling). However, other pathological gamblers exhibit more severe family, marital, and individual difficulties (including the degree of the pathological gambling severity), for which they might or might not seek specialized help. Empirical evidence increasingly supports the notion that the nature of the population of pathological gamblers is heterogeneous. For example, Toneatto et al. (2008) investigated the occurrence of spontaneous remission and found that the pathological gambling severity was higher among gamblers who had engaged in formal treatment (i.e., clinical samples). Moreover, these gamblers exhibited more negative consequences compared to individuals with nonclinical pathological gambling (i.e., a community sample). A recent study (Jiménez-Murcia et al., 2013) has identified the following three clusters of young pathological gamblers: individuals with less psychopathological problems and 
more functional personality traits, individuals with more emotional problems, and individuals with more severe psychopathological disorders.

The results of this study allow us to reflect on some interventional issues. The heterogeneity of pathological gamblers suggests that clinical interventions consider the intragroup differences. This way, it makes sense that each intervention is indeed a unique and personalized intervention focused on the characteristics of that particular case. According to Milosevic and Ledgerwood (2010), it seems important to develop intervention techniques that take into account individual differences evidenced in the case presented. Standardized clinical protocols must be used creatively by introducing, where necessary, adjustments that make them more specific to that particular case. Independently of the intervention model or type (individual, family, or couple), the work with this population should consider the aspects included in the ISMPG, such as context, family, couple, and individual variables, and the relations between them, especially in the most severe cases. In addition, the problems seem more evident when the condition is already crystallized, suggesting a silent progression problem. In this sense, it might be important to sensitize the population in general, and the gambler community, for these and other problem characteristics, such as those illustrated in ISMPG, focusing on promotion campaigns for responsible gambling.

\section{LIMITATIONS}

This study has a number of limitations, with the small sample size across groups and specifically for the PG group being the most notable. In addition, the nonprobabilistic nature of the study population, which was recruited through convenience sampling, does not allow for the generalization of these results. Nevertheless, this study contributes to current knowledge regarding pathological gamblers by emphasizing the heterogeneity of this group and the relevance of family, marital, and individual variables to pathological gambling.

\section{CONCLUSION}

In sum, pathological gamblers exhibited more family, marital, and individual difficulties compared to nonpathological gamblers (i.e., the NP and SP groups) but were a heterogeneous population, which consisted of two groups with differing levels of severity with regard to those difficulties. Although the nonpathological gamblers (i.e., the NP and SP groups) exhibited differing levels of pathological gambling severity, they did not differ from each other, suggesting that the difficulties associated with gambling are only evident at the pathological level, albeit to different degrees.

The results with regard to context (i.e., social acceptance and accessibility) and family of origin (except for the larger number of relatives with 
gambling problems) were not consistent with the predictions of the ISMPG, as no differences were evident among the groups. Future studies should focus on the various types of pathological gamblers and recruit more diversified and representative samples, particularly with regard to gender, as this will represent a valuable contribution.

\section{NOTE}

1. This property alludes to the idea that the functioning of living beings is directed by the principle that an identical end state can be reached from different initial conditions, whereas similar initial conditions might lead to different end states (Alarcão, 2006).

\section{FUNDING}

Funding support for this project was provided by grant number SFRH/BD/ $71001 / 2010$ from the Foundation for Science and Technology (FCT) in Portugal.

\section{REFERENCES}

Alarcão, M. (2006). (Des) Equilíbrios familiares: Uma visão sistémica [Family (in) balances: A systemic view] (6th ed.). Coimbra, Portugal: Quarteto.

American Psychiatric Association (APA). (2000). Diagnostic and statistical manual of mental disorders (4th ed.-TR). Washington, DC: Author.

American Psychiatric Association. (2013). Diagnostic and statistical manual of mental disorders (5th ed.). Washington, DC: Author.

American Psychological Association. (2002). Ethical principles of psychologists and code of conduct. Washington, DC: Author.

Ashley, L. L., \& Boehlke, K. K. (2012). Pathological gambling: A general overview. Journal of Psychoactive Drugs, 44(1), 27-37. doi:10.1080/02791072.2012.662078

Barrault, S. S., \& Varescon, I. I. (2012). Psychopathology in online pathological gamblers: A preliminary study. L'encéphale: Revue De Psychiatrie Clinique Biologique et Thérapeutique, 38, 156-163. doi:10.1016/j.encep.2011.01.009

Berger, P. (2012). Quality of life in pathological gambling. European Psychiatry, 27(1), 1. doi:10.1016/S0924-9338(12)74178-0

Blaszczynski, A., \& Nower, L. (2002). A pathways model of problem and pathological gambling. Addiction, 97, 487-499. doi:10.1046/j.13600443.2002.00015.x

Bowen, M. (1978). Family therapy in clinical practice. New York, NY: Aronson.

Brieva, J. R. (2006). Ludopatía: El otro lado del juego [Ludopathy: The other side of playing]. Índice. Revista Estadística y Salud, 19, 9-11.

Cabral, L. M. (2013, January 2). Santa Casa com receita recorde nos jogos sociais [Holy House of Mercy gets record income from social games]. Diário de Notícias. Retrieved from http://www.dn.pt/especiais/interior.aspx?content_id=2972288\&especial=Revistas\%20de\%20Imprensa\&seccao=TV\%20e\%20MEDIA 
Canavarro, M. C. (1999). Inventário de Sintomas Psicopatológicos: BSI [Inventory of Psychopathological Symptoms: BSI]. In M. Simões, M. Gonçalves, \& L. Almeida (Eds.), Testes e provas psicológicas em Portugal (Vol. 2, pp. 95-109). Braga, Portugal: APPORT/SHO.

Ciarrocchi, J. W. (1987). Severity of impairment in dually addicted gamblers. Journal of Gambling Behavior, 3(1), 16-26. doi:10.1007/BF01087474

Ciarrocchi, J. W. (2001). Counseling problem gamblers: A self-regulation manual for individual and family therapy. San Diego, CA: Academic Press.

Ciarrocchi, J., \& Hohmann, A. (1989). The family environment of married male pathological gamblers, alcoholics, and dually addicted gamblers. Journal of Gambling Behavior, 5, 283-291. doi:10.1007/BF01672429

Clímaco, M. I. (2004). O jogo patológico: A adição menos visível [Pathological gambling: The least visible addiction]. Revista Portuguesa de Clinica Geral, 20, 121-134.

Cohen, J. (1988). Statistical power analysis for the behavioral sciences. Hillsdale, NJ: Erlbaum.

Cohen, J. (1992). Power primer. Psychological Bulletin, 112(1), 155-159. doi:10.1037/ 0033-2909.112.1.155

Cunha, D., \& Relvas, A. P. (2014a). Pathological gambling and couple: Towards an integrative systemic model. Journal of Gambling Studies, 30, 213-228. doi:10.1007/s10899-013-9366-9

Cunha, D., \& Relvas, A. P. (2014b). Pathological gambling, psychopathology and family variables in a non-clinical sample. Manuscript submitted for publication.

Cunha, D., \& Relvas, A. P. (in press). Qualidade de Vida (QOL): Versão reduzida. In A. P. Relvas \& S. Major (Eds.), Instrumentos de avaliação familiar: Vulnerabilidade, stress e adaptação [Family assessment measures: Vulnerability, stress and adaptation] (Vol. II). Coimbra, Portugal: Imprensa da Universidade de Coimbra.

Cunha, D., Silva, J. T., Vilaça, A., Gonçalves, S., \& Relvas, A. P. (2014). Escala de Congruência (EC): Estudos de adaptação para a população portuguesa [Congruence Scale (CS): Studies for adaptation to the Portuguese population]. Revista Iberoamericana de Diagnóstico Y Evaluación e Avaliação Psicológica, 38, 181-198.

Cunha, D., Sotero, L., \& Relvas, A. P. (in press). The pathological gambler and his spouse: How do their narratives match? Journal of Gambling Issues.

Custer, R. L., \& Milt, H. (1985). When luck runs out: Help for compulsive gamblers and their families. New York, NY: Facts on File.

Darbyshire, P., Oster, C., \& Carrig, H. (2001). Children of parent(s) who have a gambling problem: A review of the literature and commentary on research approaches. Health and Social Care in the Community, 9, 185-193. doi:10.1046/j.0966-0410.2001.00302.x

Derogatis, L. R., \& Spencer, P. M. (1982). Administration and procedures: BSI. Manual I. Baltimore, MD: Clinical Psychometric Research.

Desai, R., \& Potenza, M. (2008). Gender differences in the association between pastyear gambling problems and psychiatric disorders. Social Psychiatry and Psychiatric Epidemiology, 43, 173-183. doi:10.1007/s00127-007-0283-z

Desai, R., Potenza, M., Krishnan-Sarin, S., \& Cavallo, D. (2007). Gambling behavior among high school students in the state of Connecticut (Report to CT Department of Mental Health and Addiction Services and CT Department of Education). Retrieved from http://www.ct.gov/dmhas/lib/dmhas/pgs/yalereport.pdf 
Dickson-Swift, A., James, E., \& Kippen, S. (2005). The experience of living with a problem gambler: Spouses and partners speaks out. Journal of Gambling Issues, 13(13), 1-13. doi:10.4309/jgi.2005.13.6

Domínguez-Álvarez, A. M. (2009). Epidemiología y factores implicados en el juego patológico [Epidemiology and factors involved in pathological gambling]. Apuntes de Psicología, 27(1), 3-20.

Dowling, N., Smith, D., \& Thomas, T. (2009). The family functioning of female pathological gamblers. International Journal of Mental Health and Addiction, 7(1), 29-44. doi:10.1007/s11469-007-9126-0

Felsher, J. R., Derevensky, J. L., \& Gupta, R. (2003). Parental influences and social modelling of youth lottery participation. Journal of Community $\&$ Applied Social Psychology, 13, 361-377. doi:10.1002/casp.738

Ferentzy, P., \& Turner, N. E. (2013). The history of problem gambling: Temperance, substance abuse, medicine, and metaphors. New York, NY: Springer Science + Business Media. doi:10.1007/978-1-4614-6699-4

Fraley, C., \& Raftery, A. E. (1998). How many clusters? Which clustering method? Answers via model-based cluster analysis. The Computer Journal, 41, 578-588. doi:10.1093/comjnl/41.8.578

González, A. (1989). Juego patológico: Una nueva adicción [Pathological gambling: A new addiction]. Madrid, Spain: Canal Comunicaciones.

Goodman, L. A. (1961). Snowball sampling. Annals of Mathematical Statistics, 32(1), 148-170. doi:10.1214/aoms/1177705148

Grant, J. E., \& Kim, S. W. (2001). Demographic and clinical features of 131 adult pathological gamblers. Journal of Clinical Psychiatry, 62, 957-962. doi:10.4088/ JCP.v62n1207

Gupta, R., \& Derevensky, J. L. (1997). Familial and social influences on juvenile gambling behavior. Journal of Gambling Studies, 13, 179-192. doi:10.1023/ A:1024915231379

Hardoon, K., Derevensky, J., \& Gupta, R. (2002). An examination of the influence of familial, emotional, conduct and cognitive problems, and byperactivity upon youth risk-taking and adolescent gambling problems (Report to the Ontario Problem Gambling Research Centre). Retrieved from http://youthgambling. mcgill.ca/en/PDF/OPGRC.pdf

Harvey, P., Trudel, G., Poirier-Arbour, A., \& Boyer, R. (2007). Le jeu pathologique et l'expression de la colère au sein du couple [Pathological gambling and expression of anger within the couple]. Paper presented at the XXIXème congrès annuel de la Société Québécoise pour la Recherche en Psychologie, Sherbrooke, Canada.

Instituto Nacional de Estatística (INE) [Statistics Portugal]. (2009). Tipologia de áreas urbanas [Typology of urban areas]. Retrieved from http://smi.ine.pt/Versao/ Detalhes/1961

Jiménez, A. (2002). Los juegos de azar: Juego social y ludopatía [Games of chance: Social games and ludopathy]. Zaragoza, Spain: Diputación General de Aragón, Universidad de Zaragoza.

Jiménez-Murcia, S., Álvarez-Moya, E. M., Stinchfield, R., Fernández-Aranda, F., Granero, R., Aymamí, N., \& Menchón, J. (2010). Age of onset in pathological gambling: Clinical, therapeutic and personality correlates. Journal of Gambling Studies, 26, 235-248. doi:10.1007/s10899-009-9175-3 
Jiménez-Murcia, S., Granero, R., Stinchfield, R., Fernández-Aranda, F., Penelo, E., Savvidou, L. G., \& Menchón, J. M. (2013). Typologies of young pathological gamblers based on sociodemographic and clinical characteristics. Comprehensive Psychiatry, 54, 1153-1160. doi:10.1016/j.comppsych.2013.05.017

Kalischuk, R., Nowatzki, N., Cardwell, K., Klein, K., \& Solowoniuk, J. (2006). Problem gambling and its impact on families: A literature review. International Gambling Studies, 6(1), 31-60. doi:10.1080/14459790600644176

Kerr, M. E., \& Bowen, M. (1988). Family evaluation: An approach based on Bowen theory. New York, NY: Norton.

King, S. M., Abrams, K., \& Wilkinson, T. (2010). Personality, gender, and family history in the prediction of college gambling. Journal of Gambling Studies, 26, 347-359. doi:10.1007/s10899-009-9163-7

Korn, D. A. (2000). Expansion of gambling in Canada: Implications for health and social policy. Canadian Medical Association, 163(1), 61-64.

Kusyszyn, I. (1978). Compulsive gambling: The problem of definition. International Journal of Addictions, 13, 1095-1101. doi:10.3109/10826087809039329

Ladouceur, R. (2002). Understanding gambling and problem gambling: A step in the right direction. Lecture Series, 1(1), 1-10.

Lee, B. (2002). Well-being by choice not by chance: An integrative system based couple treatment model for problem gambling (Report to Ontario Problem Gambling Research Centre). Retrieved from https://www.uleth.ca/dspace/bitstream/handle/10133/568/Well_Being_Lee.pdf\%3Fsequence\%3D1

Lesieur, H. R., \& Blume, S. B. (1987). The South Oaks Gambling Screen (SOGS): A new instrument for the identification of pathological gamblers. American Journal of Psychiatry, 144, 1184-1188. doi:10.1176/ajp.144.9.1184

Lopes, H. (2009). Epidemiologia de dependência do jogo a dinheiro em Portugal [Epidemiology of gambling dependence in Portugal]. Retrieved from http://ww3. scml.pt/media/arquivo/2009/outubro/conferencia_estudo.pdf

Lorenz, V., \& Yaffee, R. (1986). Pathological gambling: Psychosomatic, emotional and marital difficulties as reported by the gambler. Journal of Gambling Behavior, 2(1), 40-49. doi:10.1007/BF01019933

Lourenço, M. (2006). Casal: Conjugalidade e ciclo evolutivo [The couple: Conjugality and evolutionary cycle] (Unpublished doctoral thesis). Faculty of Psychology and Educational Sciences of University of Coimbra, Coimbra, Portugal.

Madeira, C. (2012, May 21). Lucros dos jogos Santa Casa crescem 20\% [The Holy House of Mercy profit increases by 20\%]. Económico, Retrieved from http:// economico.sapo.pt/noticias/lucros-dos-jogos-santa-casa-crescem-20_14491

Major, S., Rodríguez-González, M., Miranda, C., Rousselot, M., \& Relvas, A. P. (2014). Inventário de Diferenciação do Self-Revisto [Inventory of Self-DifferentiationRevised]. In A. P. Relvas \& S. Major (Eds.), Avaliação familiar: Funcionamento e intervenção (Vol. I, pp. 81-111). Coimbra, Portugal: Imprensa da Universidade de Coimbra.

McCormick, R. A., \& Taber, J. I. (1987). The pathological gambler: Salient personality variables. In T. Galski (Ed.), The handbook of pathological gambling (pp. 9-39). Springfield, IL: Thomas. 
Milosevic, A., \& Ledgerwood, D. M. (2010). The subtyping of pathological gambling: A comprehensive review. Clinical Psychology Review, 30, 988-998. doi:10.1016/ j.cpr.2010.06.013

Montero, J., \& Megías-Lizancos, F. (2011). El paciente ludópata: Dificultades em la familia y su entorno social [The patient with ludopathy: Family and social difficulties]. Paper presented at the XII Congresso Virtual de Psiquiatria Interpsiquis (February 1-28, 2011; virtual congress). Retrieved from http://www.psiquiatria. com/bibliopsiquis/handle/10401/2399

Moody, G. (1990). Quit compulsive gambling. Wellingborough, UK: Thorsons.

Moore, S., Thomas, A., Kyrios, M., Bates, G., \& Meredyth, D. (2011). Gambling accessibility: A scale to measure gambler preferences. Journal of Gambling Studies, 27(1), 129-143. doi:10.1007/s10899-010-9203-3

Moran, E. (1970). Varieties of pathological gambling. The British Journal of Psychiatry, 116, 593-597. doi:10.1192/bjp.116.535.593

Mythily, S., Edimansyah, A., Qiu, S., \& Munidasa, W. (2011). Quality of life in pathological gamblers in a multiethnic Asian setting. Annals Academy of Medicine, 40, 265-268.

Narciso, I., \& Costa, M. E. (1996). Amores satisfeitos, mas não perfeitos [Love: Satisfied but not perfect]. Cadernos De Consulta Psicológica, 12, 115-130.

Ochoa, E., \& Labrador, F. J. (1994). Juego patológico [Pathological gambling]. Barcelona, Spain: Plaza \& Janés.

Olson, D. H., \& Barnes, H. (1982). Quality of life. In D. Olson, H. McCubbin, H. Barnes, A. Larsen, M. Muxen, \& M. Wilson (Eds.), Family inventories (pp. 137148). St. Paul, MN: University of Minnesota, Family Social Science.

Pallant, J. (2001). SPSS survival manual: A step by step guide to data analysis using SPSS for Windows. Buckingham, UK: Open University Press.

Patrick, S., Sells, J. N., Giordano, F. G., \& Tollerud, T. R. (2007). Intimacy, differentiation, and personality variables as predictors of marital satisfaction. The Family Journal, 15, 359-367. doi:10.1177/1066480707303754

Peleg, O. (2008). The relation between differentiation of self and marital satisfaction: What can be learned from married people over the course of life? Academic Medicine, 84, 388-401.

Petry, N. M. (2005). Pathological gambling: Etiology, comorbidity, and treatment. Washington, DC: American Psychological Association.

Potenza, M. N. (2013). Neurobiology of gambling behaviors. Current Opinion in Neurobiology, 23, 660-667. doi:10.1016/j.conb.2013.03.004

Rousseeuw, P. J. (1998). Silhouettes: A graphical aid to the interpretation and validation of cluster analysis. Journal of Computation and Applied Mathematics, 20, 53-65.

Shaffer, H. J., Bilt, J. V., \& Hall, M. N. (1999). Gambling, drinking, smoking and other health risk activities among casino employees. American Journal of Industrial Medicine, 36, 365-378. doi:10.1002/(SICI)1097-0274(199909)36:3<365::AIDAJIM4>3.0.CO;2-I

Simões, M. (1994). Investigações no âmbito da aferição nacional do Teste de Matrizes Progressivas de Raven (M.P.C.R.) [Studies on the national assessment of Raven's Progressive Matrices (M.P.C.R.)] (Unpublished doctoral thesis). Faculty of Psychology and Educational Sciences of University of Coimbra, Coimbra, Portugal. 
Skowron, E. A. (2000). The role of differentiation of self in marital adjustment. Journal of Counseling Psychology, 47, 229-237. doi:10.1037/0022-0167.47.2.229

Skowron, E. A., \& Schmitt, T. A. (2003). Assessing interpersonal fusion: Reliability and validity of a new DSI fusion with others subscale. Journal of Marital and Family Therapy, 29, 209-222.

Spanier, G. B. (1976). Measuring dyadic adjustment: New scales for assessing the quality of marriage and similar dyads. Journal of Marriage and the Family, 38(1), $15-28$.

Stratton, P., Bland, J., Janes, E., \& Lask, J. (2010). Developing a practicable outcome measure for systemic family therapy: The SCORE. Journal of Family Therapy, 32, 232-258.

Teo, P., Mythily, S., Anantha, S., \& Winslow, M. (2007). Demographic and clinical features of 150 pathological gamblers referred to a community addictions program. Annals of the Academy of Medicine, 36, 165-168.

Toneatto, T., Cunningham, J. A., Hodgins, D. C., Adams, M., Turner, N. E., \& KoskiJannes, A. (2008). Recovery from problem gambling without formal treatment. Addiction Research \& Theory, 16, 111-120.

United Nations Educational Scientific and Cultural Organization Institute for Statistics. (2012). International Standard Classification of Education-ISCED 2011. Quebec, Canada: Author.

Vilaça, M., Silva, J., \& Relvas, A. P. (2014). Systemic Clinical Outcome Routine Evaluation (SCORE-15). In A. P. Relvas \& S. Major (Eds.), Avaliação familiar: Funcionamento e intervenção (Vol. I, pp. 25-47). Coimbra, Portugal: Imprensa da Universidade de Coimbra.

Weinstock, J., Massura, C. E., \& Petry, N. M. (2013). Professional and pathological gamblers: Similarities and differences. Journal of Gambling Studies, 29, 205-216. doi:10.1007/s10899-012-9308-y 